\title{
Reply
}

\section{The pragma-dialectician's dilemma: Reply to Garssen and van Laar}

\section{HARVey Siegel}

Department of Philosophy

University of Miami

P.O. Box 248054

Coral Gables, FL 33124-4670

U.S.A.

Email:hsiegel@miami.edu

\section{JOHN BIRO}

Department of Philosophy

University of Florida

330 Griffin-Floyd Hall

Gainesville, FL 32611-8545

U.S.A.

Email: jbiro@ufl.edu

\begin{abstract}
Garssen and van Laar in effect concede our main criticism of the pragma-dialectical approach. The criticism is that the conclusions of arguments can be 'P-D reasonable' yet patently unreasonable, epistemically speaking. The concession consists in the claim that the theory "remains restricted to the investigation of standpoints in the light of particular sets of starting points" which are "up to individual disputants to create" and the admission that all the relevant terms of normative appraisal have been redefined. We also discuss their criticisms of the epistemic account of argumentation and argument evaluation and raise some new questions about the approach they defend.
\end{abstract}

Resumé:

Keywords: argumentation, arguments, epistemic theory, justification, normative evaluation, pragma-dialectical theory.

(C) Harvey Siegel and John Biro. Informal Logic, Vol. 30, No. 4 (7010) nn 457-480 


\section{Introduction}

In "A pragma-dialectical response to objectivist epistemic challenges," Bart Garssen and Jan Albert van Laar (Garssen and van Laar 2010) defend the pragma-dialectical approach developed by Frans van Eemeren and Rob Grootendorst against criticisms we have leveled at it and raise some objections against the epistemic approach we advocate. After a brief discussion of their response to our main criticism (Sections 2 and 3), we take up these objections, many of which center on whether an account of argument evaluation should be committed to 'justificationism' (Sections 4-7). We argue that our opponents face a dilemma: either they retain an element of justification and, in doing so, in effect endorse the epistemic approach or they exclude all such elements and thereby change the subject. We then address two additional complaints about the epistemic approach (Sections 8 and 9). We discuss the proposal for a pragma-dialectical redefinition of the normative terms used in evaluating arguments (Section 10) and close with a question about the viability of conceiving of disputes such as the present one in terms of the pragma-dialectical approach.

\section{The central epistemic objection to pragma-dialectics}

Our basic criticism of the pragma-dialectical approach to the evaluation of arguments and argumentation is straightforward. According to that approach, argumentation - and the resulting beliefs or acceptance of standpoints - is rational or reasonable if the arguer "performs only speech acts which accord with a system of rules acceptable to all the discussants which furthers the creation of a dialectic which can lead to a resolution of the dispute at the center of the discussion" (van Eemeren and Grootendorst 1984, p. 18; cf. van Eemeren and Grootendorst 1992, pp. 6-11; van Eemeren and Grootendorst 2004, p. 16). This makes 'rationality' or 'reasonableness' a function of two things: the possibility of the resolution of the dispute ('problem validity'), and reaching that resolution in accordance with discussant-agreed-upon rules and starting points ('conventional validity'). Our criticism is that the beliefs and standpoint-evaluations that result from such discussions can be rational or reasonable in this pragma-dialectical sense, while being irrational or unreasonable, epistemically speaking. This can happen in either or both of two ways. The discussants may share, and rely on, unjustified beliefs, and they may accept, and use, problematic rules of inference or reasoning. In both cases the resulting resolution may be rational in the pragma-dialectical sense-henceforth 'PD-rational' - but patently irrational from the epistemic point of view. As we have put it elsewhere, "The difficulty [with PD- 
rationality] is that the participants might abide by the code of conduct and resolve their dispute but in ways which render that resolution unjustified or irrational" (Biro and Siegel 1992, p. 90; cf. Siegel and Biro 1997, pp. 282-5; Biro and Siegel 2006, pp. 6-7). PD-rational resolutions are obviously rational in the stipulated PD sense, but, if we are right, they need not be rational in the epistemic sense of showing the standpoints to be justified. ${ }^{1}$ But it is the latter sort of rationality that is crucial for the evaluation of arguments (Biro and Siegel 1992, p. 91-2, 96-9; Siegel and Biro 1997, p. 278, 281-5; Biro and Siegel 2006, pp. 6-7).

We appreciate Garssen and van Laar's (2010) response to our criticism. It is clear and very helpful in clarifying the issues at the heart of the disagreement between pragma-dialectitians and advocates of the epistemic view. In this reply we hope to show that the view they espouse faces a dilemma. It must either concede our basic criticism and, in effect, sign on to an epistemic account or be seen as changing the subject and having nothing to say about the evaluation of arguments in the usual sense of telling good arguments from bad.

Garssen and van Laar argue that our criticisms of the pragmadialectical approach "are based on incorrect assumptions." First, they say, we incorrectly "claim that the pragma-dialectical model is not genuinely normative for the reason that the norms that make up the model do not guarantee rational outcomes." Second, we mistakenly "claim that the pragma-dialectical approach does not and cannot live up to its aspirations derived from the critical rationalist philosophy" (2010, p. 123). We begin by addressing these claims in turn. We then comment on their discussion of the so-called Münchhausen trilemma; their further criticisms of our epistemic approach (that we do not take fallibilism seriously enough, that we do not pay sufficient attention to the social context in which argumentation takes place, and that the epistemic approach unduly restricts the range of issues that arguments can address); their defense against the charge that P-D theory, like the critical rationalism they espouse, contains 'a whiff of justificationism'; their criticisms of our proffered counter-examples to P-D theory; and their redefinition of the key terms of argument analysis and evaluation. Finally, we raise a difficulty concerning the application of that theory to the present dispute.

\footnotetext{
${ }^{1}$ We need hardly point out that it would be too much to ask even of an epistemically good argument that it show its conclusion to be true. We may-and do-hope that it is but know that we are sometimes justified in believing a falsehood.
} 


\section{Pragma-dialectics and normativity}

"The problem validity of the discussion rules in general, and of the appropriateness of the argumentation and reasoning schemes in particular, is the result of assessing them, not in view of their epistemic worth, but rather in view of the degree to which they promote criticism, something insufficiently appreciated by Biro and Siegel, in our opinion" (Garssen and van Laar 2010, p. 129). We do appreciate, of course, that P-D does not assess arguments in terms of their epistemic worth - this has been our main complaint against it. As for assessing them in terms of the degree to which they promote criticism, that proposal (as we argue below) has also to face the dilemma we are posing: either criticism and coping with criticism are themselves subject to evaluation in terms of epistemic criteria or the fact that an argument promotes them has no bearing on its merits. More important, their positive point here grants our basic criticism that rules can be problem valid and conventionally valid, and can effectively promote criticism, yet be epistemically defective. As the cited passage makes clear, on the pragma-dialectical view, discussion rules, reasoning schemes, and argumentation are assessed not in terms of their epistemic worth but according to the degree to which they promote criticism. Later we will address the question of what promotion of criticism comes to in P-D (Sections 4, 10).

Our main complaint, in a nutshell, comes to this: Problem validity + conventional validity do not yield the right kind of normativity. It is not that they are not in some sense normative: they are proposals for standards to which arguers ought to strive to conform. But in this sense, normativity comes cheap. A standard is by definition normative, hence proposing any standard for evaluating arguments is tantamount to proposing a normative theory. What is in dispute is whether P-D standards are the right ones, that is, whether they pick out the properties the possession of which makes an argument a good one. In conceding that critical discussions that honor the P-D standards can result in the resolution of disputes, the acquisition of new beliefs, and the acceptance of standpoints that are not rational or reasonable in the straightforward sense that the reasons offered in their support tend at least to establish their truth or to enhance their epistemic status, Garssen and van Laar in effect grant our central contention, namely, that the P-D theory does not evaluate arguments in terms of the right properties.

As far as this dispute is concerned, we could stop here. But things are obviously not quite as simple as this: P-D theorists do not concede that epistemic properties are the right ones in terms of which to evaluate arguments. So, we will continue, in order to establish more fully that Garssen and van Laar do indeed concede our claim about P-D, to show that they at the same time rely on epis- 
temic standards themselves, and, most importantly, to address what we are suggesting is the real issue: what standards should be used in evaluating arguments.

\section{Justificationism, positive support, and the primacy of criti- cism}

In Siegel and Biro (2008), we argued that despite their best efforts to avoid it, P-D theorists actually depend on the justificationism they claim to eschew (see also Lumer 2010). Garssen and van Laar reject our claim and argue that pragma-dialectical theory admits to "not even a whiff of justificationism" (Garssen and van Laar 2010, p. 138). Instead, they suggest, dialectic is "the study of conversational norms that promote criticism" (Garssen and van Laar 2010, p. 130), and criticism is not a matter of justification. By positing this sharp dichotomy between justification and criticism, they are committed to the view that criticism is independent of justification. This, we think, is a view that cannot survive critical scrutiny.

What is 'justificationism'? As deployed in accounts of 'norms of reasonableness', the term admits of at least two interpretations: a judgment is reasonable if the standpoint being judged is either legitimized definitively, or (less demandingly) enjoys adequate positive support by way of reasons and/or evidence (Siegel and Biro 2008, p. 195; "definitively" is the term used by van Eemeren and Grootendorst 2004, p. 131). We agree with P-D theorists that the former is too strong, but we think that the latter is both appropriate and necessary for an adequate account of argument evaluation. So, our disagreement with P-D theorists concerns this latter sense: we embrace 'justificationism' in the sense that arguments, to be good, must be such that their conclusions enjoy adequate positive support from their premises, and our epistemic account spells this out in terms of increases in knowledge or justification. P-D theorists reject this, in favor of their dialectical, critical rationalist account of reasonableness:

To critical rationalists, the idea of a systematic critical scrutiny of all fields of human thought and activity is the principle that serves as the starting point for the resolution of problems. In this approach, conducting a critical discussion is made the point of departure for the conception of reasonableness - which implies the adoption of a dialectical approach. As we have indicated, argumentation in a dialectical approach is regarded as part of a procedure for resolving a difference of opinion on the acceptability of one or more standpoints by means of a critical discussion... The reasonableness of the procedure is derived 
from the possibility it creates to resolve differences of opinion (its problem validity) in combination with its acceptability to the discussants (its conventional validity). In this connection, the rules of discussion and argumentation developed in a dialectical theory of argumentation must be scrutinized in terms of both their problem-solving effectiveness and their intersubjective acceptability. (van Eemeren and Grootendorst 2004, pp. 131-2.)

On the P-D view, then, a given procedure (and, presumably, the rules that license it) is reasonable if and only if it is both problem valid and conventionally valid. This, we trust it is clear, is quite a different thing from both a conclusion's being reasonable, and a belief in a conclusion's being reasonable. We have suggested elsewhere that perhaps epistemic theories and P-D theories are simply talking about two different things and are not actually in conflict but are complementary: the latter about how to conduct a critical discussion, the former about how to evaluate an argument. (Biro and Siegel 2006) If this is correct, P-D reasonableness, cashed out as it is in terms of the problem validity and conventional validity of the recommended procedure for resolving differences of opinion (given by the rules for a critical discussion) does not speak to the epistemic status of arguments or the beliefs they are used to justify. Of course, P-D theorists are well within their rights to insist that P$\mathrm{D}$ reasonableness is nevertheless straightforwardly normative in that it evaluates discussion rules and argumentation in terms of how well they promote problem validity and conventional validity (and criticism). With this we have no quarrel, other than to point out that rules and arguments that are in this sense 'reasonable' may nevertheless be completely unreasonable and their conclusions manifestly unworthy of belief.

Notice that on van Eemeren and Grootendorst's account, reasonableness is cashed out in terms of problem- and conventional validity. Garssen and van Laar say, rather, that the normative evaluation of "the discussion rules in general, and of the appropriateness of the argumentation and reasoning schemes in particular, is the result of assessing them, not in view of their epistemic worth, but rather in view of the degree to which they promote criticism" (Garssen and van Laar 2010, p. 129). We do not wish to take sides in this in-house dispute within the P-D camp, but we think it is worth pointing out this tension: on the original P-D view, the normative evaluation of argumentation is a matter of problem- and conventional validity; on the Garssen and van Laar view, it is a matter of the promotion of criticism. Of course van Eemeren and Grootendorst also emphasize the importance of criticism, while Garssen and van Laar, too, insist upon the importance of problemand conventional validity; perhaps the most charitable interpreta- 
tion is that for all four authors, all three of these things - problem validity, conventional validity, and the tendency to promote criticism - are integral to the normative dimension of argumentation.

One reason we do not think it important to take sides in this dispute - perhaps these different emphases can be reconciled - is that we think that both versions face major difficulties. We have already pointed out those we find with the original one. What of the new one, that the normative evaluation of the discussion rules, and the appropriateness of argumentation and reasoning schemes, is a matter of the degree to which they promote criticism?

Consider Garssen and van Laar's claim that promoting criticism does not require offering positive support. Can criticism be understood independently of positive support? We think not. Consider two critical discussions. In the first a standpoint $s$ is rejected by the discussants on the basis of criticism $c$. In the second the standpoint $s$ is rejected by the discussants on the basis of criticism $c^{\prime}$. What should we say about the normative quality of the argumentation in the two discussions? It seems obvious that we cannot say anything yet, because we are not in a position to judge the epistemic merit of the criticisms. Let the standpoint and criticisms be as follows:

$s$ : Amsterdam is the most crowded European city.

$c$ : Amsterdam has the lowest density of European cities, as measured by number of people per square meter of land.

$c^{\prime}:$ Amsterdam has many beautiful canals.

We take it as obvious that $c$, if true, constitutes a serious criticism of $s$, while $c^{\prime}$ does not. That is, some criticisms are better than others. ' $\neg s$, because $c$ ' is a better argument than ' $\neg s$, because $c$ '. If this is right, it shows two things. First, 'the promotion of criticism' cannot by itself be an adequate measure of argument quality, because criticisms vary in their degree of relevance and force. Even more importantly, we think, the quality of criticism depends upon positive support; the two cannot be as sharply distinguished as Garssen and van Laar require. If $c$ is indeed a good criticism of $s$, it gives us a good reason not to believe $s$ : in the example, if Amsterdam indeed has the lowest density, that constitutes both (1) a good criticism of 'Amsterdam is the most crowded city', and (2) a good reason not to believe that Amsterdam is the most crowded city. Criticism and positive support cannot be separated. Indeed, the point can be put more strongly: a criticism, to have force, must involve positive support. (This point is central to critical discussion of Popper's version of critical rationalism; see Siegel and Biro 
2008, pp. 197-8.) There is a symmetrical relationship between criticism and positive support that undermines any attempt to reject justificationism, or positive support, altogether, while resting the normative evaluation of arguments on how well they promote criticism.

\section{The Münchhausen trilemma}

The trilemma is supposed to spell the death-knell of justificationism, because any theory of justification that relies on the notion of positive support must end in one of three equally unacceptable options: an infinite regress, a dogmatic or arbitrary (and so unjustified) stopping point, or circular reasoning. These being the only options, each thought to be clearly unacceptable, the conclusion to be drawn, according to critical rationalists like Hans Albert, Karl Popper, and the P-D theorists, is that we must abandon justificationism, and with it the notion of positive support (Garssen and van Laar 2010, pp. 131-3; cf. Siegel and Biro 2008, pp. 195-202).

The first question to ask is: Are these three possible end points of justificatory arguments all in fact bad, from the epistemic point of view? Here we will not argue that any of them are in fact not bad, but we would like to point out briefly that in fact two of them (infinitism and circularity) have been defended as legitimate in recent literature in epistemology. (See Klein 1999, 2000 on infinite regress, Goodman 1983 on virtuous circularity, Lehrer 2000, 2003 on coherence, etc.) The epistemological issues here concerning justification are far more complex than the quick appeal to the trilemma might suggest.

The second question to be asked is: Are these three options the only ones, or is it possible for the premises of an argument to provide positive support for the conclusion without falling into infinite regress, arbitrariness or dogma, or circular reasoning? While to our knowledge no serious contemporary epistemologist has defended arbitrariness or dogma as an acceptable end point of a justificatory argument, we have argued that stopping points need be neither. That is, justificatory arguments that avoid infinite regress and circularity can have stopping points that are neither arbitrary nor dogmatic (Siegel and Biro 2008, pp. 199-202). Let us explain.

Garssen and van Laar argue that a stopping point can be nonarbitrary or non-dogmatic only if it is conceived dialectically: that is, only if no challenge to it is made. If conceived non-dialectically, the demand for further justification will always be there:

From a dialectical stance it is clear where the protagonist can stop putting forward further arguments: when having arrived at the mutually agreed upon starting points of the 
discussion. From a justificationist stance, where no clear role is assigned to a critical antagonist, it cannot be made clear that $r$ does not stand in need of support. Because, a justificationist response to Biro and Siegel's proposed solution could go: "What does it matter whether or not $r$ happens to be addressed to an audience that, as a matter of fact, does not challenge $r$ ? The real issue is the objective truth and since $r$ 's truth has not yet been guaranteed, we ought to justify $r$ ". So, we fail to see a fourth way that is genuinely justificationist. (Garssen and van Laar 2010, p. 139. )

This, we think, is mistaken: a stopping point's standing in need of justification is not dependent on whether an actual challenge to it is made. Note first that the lack of a 'guarantee' is a red herring here. No guarantee (or certainty) is necessary for justification. A given premise $r$ is justified, and so rational to believe or endorse, when the total evidence for it is sufficient (in the context and for present purposes). This is rough, of course, and there are many epistemological niceties on which we could elaborate, but doing so would take us unnecessarily far afield.

Consider an example:

$p$ : The Netherlands lost the final match of the 2010 World Cup to Spain.

$p$ stands in need of support. Here are some possible supports (i.e., reasons that provide justification for believing it):

$q$ : I watched the match (on TV, the internet, or in person in South Africa).

$r$ : I read about the match (in a newspaper, a magazine, or on line).

$s$ : I overheard many discussions about the match, by people who claimed to have seen it, in the office, the pub, or the supermarket.

For ease of presentation, call the conjunction of these premises

$t: q+r+s$

We claim that, absent further, contrary (defeating or undercutting), evidence, $t$ is a non-arbitrary, non-dogmatic stopping point in the argument for $p$. That is, $t$ provides justification for believing that $p$. This does not mean that $t$ could not be called into question; 
of course it could. But if there is no good reason to call $t$ into question-no defeating evidence (e.g., contradictory news reports or discussions), no undercutting evidence (e.g., evidence of a vast, world-wide conspiracy or a hoax perpetrated by alien invaders or Las Vegas gambling houses) - then $t$ is a non-arbitrary, nondogmatic stopping point in an argument that justifies one in believing that $p$. Those readers who believe that Spain won the match in question for reasons like those in $t$ are perfectly justified in their belief. If that is so, the trilemma does not show that "justificationism', i.e., the justification of a belief, standpoint or conclusion on the basis of the positive support offered by reasons, is impossible.

For these reasons we disagree with Garssen and van Laar's conclusion: "The upshot of the Münchhausen critique is that the adoption of justificationism leads one into insurmountable problems" (Garssen and van Laar 2010, p. 132). ${ }^{2}$

\section{Further criticisms of justificationism}

Garssen and van Laar offer two additional reasons for rejecting justificationism. First, that it does not take fallibilism seriously enough:

Even if the quest for justification can be reconciled with the acknowledgement that humans are fallible, critical rationalism constitutes an approach that takes the fallibility of our cognitive capacities more seriously than justificationism. For the central idea in the critical approach is that

\footnotetext{
${ }^{2}$ Moreover, it is worth pointing out that the trilemma is not addressed to justification conceived of in dialectical terms, but only in straightforwardly epistemic terms. Garssen and van Laar take it that the Münchhausen critique shows that justificationism fails to yield "genuinely justified conclusion[s]." (ibid.) That is, the trilemma is meant to challenge justificationism as an account of the normative status that premises might afford to a conclusion or to the resulting belief in it. It is not addressed to procedures or rules of critical discussions. But it is the latter at which the norms of PD-reasonableness are aimed. This suggests that there is either (1) a conflation, in the P-D literature, between the two 'targets' of evaluation in terms of reasonableness - i.e., (a) the normative/justificatory status of standpoints/conclusions, in terms of the arguments that are offered in their support, and (b) the normative status of the rules and procedures of critical discussions, in terms of their problem validity, conventional validity, and/or tendency to promote criticism, or (2) an argument to the effect that we cannot have (a) and so should settle for (b). If there is such a conflation, it needs to be sorted out by the P-D theorists. If it is (2) that is in play, the premise, as we have just shown, is false.
} 
opinions and theories must be tested systematically and critically, and that sound arguments should be understood as contributions to such a critical examination. Merely acknowledging the possibility of shortcomings in a justification does not suffice. That is why argumentation should be situated in the kind of discussion where an antagonist has adopted the task of finding out whether the argumentation offered in support of the standpoint is sound. A weakness of justificationism is therefore that the attention is fixed on justification rather than on criticism. (Garssen and van Laar 2010, p. 132, emphasis in original.)

How are the 'testing' of opinions and theories, the 'soundness' of arguments, or the 'weakness' of justificationism to be understood, other than in terms of the presence or absence of positive epistemic support? We address this question in some detail below.

Garssen and van Laar's second objection to justificationism is that it is too impersonal:

[J] ustificationists do not pay sufficient attention to the addressee, and his points of departure....The pragmadialectical criticism against justificationism is not that it would be impossible to bring forward good reasons in support of a standpoint. The criticism is that the focus is on good reasons, conceived of as in a socially void space, instead of argumentation as a response to criticisms by a particular antagonist. (Garssen and van Laar 2010, p. 133.)

Actually, and contrary to the just-cited passage, Garssen and van Laar (like van Eemeren and Grootendorst) do argue "that it would be impossible to bring forward good reasons in support of a standpoint": that is the whole point of their appeal to the Münchhausen trilemma, and it is what their rejection of justificationism amounts to. We have already addressed that criticism. What do we say to the second criticism, that justificationism does not pay attention to the discussants, and focuses on good reasons "conceived of as in a socially void space"? We say two things. First, argumentation theory must address both argumentation, understood as an exchange of speech acts in discussion, and arguments, understood as abstract objects in which some considerations (the premises) purport to stand in particular epistemic relationships to another (the conclusion) (Biro and Siegel 2006). In considering the latter, abstracting from context and treating the elements of an argument 'as in a socially void space' is exactly the right thing to do. Second, even with respect to argumentation, justificationists need not and should not hold that argumentative exchanges do not occur in a social context. Rather, they should (and we do) hold that the epistemic 
evaluation of such exchanges is independent of the particularities of the social context in which they occur. Garssen and van Laar will be unmoved by this response, since they are not interested in such epistemic evaluation. But this just shows, from another angle, that they concede our basic criticism that the P-D approach ignores the central feature that makes arguments what they are.

\section{Is there "a whiff of justificationism" in the P-D approach?}

Surprisingly, Garssen and van Laar say, in response to our review of the literature surrounding Popper's admission of a "whiff of inductivism" in his version of critical rationalism, that we fail to show that a similar admission is necessary for P-D theorists: "Biro and Siegel seem to suggest that a similar concession to justificationism should be appropriate for pragma-dialectics. [But] the authors do not spell out the (parallel) argument that should force pragma-dialecticians to make this (parallel) concession" (Garssen and van Laar 2010, p. 137). In fact, the parallel argument is explicitly spelled out in the paper that Garssen and van Laar are discussing: "To reject "justificationism" in the sense of positive justification would be devastating to their [i.e., van Eemeren and Grootendorst's] project in at least two ways: it would undercut the possibility of any argument(ation) succeeding in the sense of providing interlocutors with good reasons to accept or reject any given standpoint at issue; and it would undercut their own many impressive efforts to defend the pragma-dialectical view they champion. Without the possibility of positive justification, there can be no possibility of their arguments establishing the epistemic worthiness of their own view" (Siegel and Biro 2008, p. 199).

Instead of addressing these two ways in which (according to us) P-D theorists need to make a concession to justificationism, Garssen and van Laar argue that in critical discussions, "justification" in the justificationist's sense of positive support is not necessary, and that for this reason P-D theorists need make no concession to justificationism:

First, in a dialectical sense of 'justify', the outcome of a discussion can, indeed, (but need not) be used to justify a proposition. This is not indicative of a whiff of justificationism. Suppose, two discussions, D and D', have been conducted, such that the protagonist in $\mathrm{D}$ defends that $\mathrm{S}$ while the protagonist in D' defends that not-S. Suppose further that both discussions proceed from starting points that some person $\mathrm{P}$ underwrites, that all propositions that $\mathrm{P}$ considers relevant for this issue are in fact starting points of D and D', that the parties in D and D' have performed 
the moves that $\mathrm{P}$ would consider the pertinent moves, and that $\mathrm{D}$ and $\mathrm{D}$ ' do not contain any violation of a rule for critical discussion. Finally suppose that $\mathrm{S}$ has been defended successfully in D but that not-S has not been defended successfully in $\mathrm{D}^{\prime}$ (or that $\mathrm{S}$ has been defended more successfully in D as compared to how not-S has fared in D'). Then, other things being equal, it can be expected that this person $\mathrm{P}$ will prefer $\mathrm{S}$ as his personal conviction over not-S. A person, $\mathrm{Q}$, could even try to convince $\mathrm{P}$ of $\mathrm{S}$ by referring to these discussions $\mathrm{D}$ and $\mathrm{D}$ ' and their outcomes. That way of arguing could be a success for Q.

The fact that this kind of argumentation can be in line with the norms for critical discussion, however, does not mean that the pragma-dialectical approach allows for a "whiff of justificationism". Every argument can be understood as part of a mutual, critical examination, and this special argument (that takes the outcome of D and D' as its starting points), too, should be seen as a response to an antagonist (P) who is testing the standpoint critically. So, the special argument does not constitute justification, unless we understand this term in a dialectical fashion.

Second, the parties' interest in resolving differences of opinion is not necessarily motivated by the aim of arriving at true or acceptable standpoints. We readily agree that critical discussions can be instrumental for dialogue participants who are primarily interested in finding out whether the standpoint at issue is acceptable "as such" (i.e., expressing a true proposition, or an action that is really recommendable, or an evaluation that is genuinely appropriate), rather than merely defensible against a particular antagonist with particular starting points. But this aim for a standpoint that is "as such" acceptable is not the goal of critical discussion as defined in pragma-dialectics. The desired result of any critical discussion is either that the standpoint has been successfully defended against an antagonist who has been [sic] committed himself to a particular set of starting points, or that the standpoint has been successfully criticized from that particular stance. So, different from Popper's philosophy of science, which is motivated by the quest for true theories, the pragmadialectical theory of argumentation remains restricted to the investigation of standpoints in the light of particular sets of starting points. Given that the pragma-dialectical theory is about defending standpoints against an addressee with a particular set of commitments, rather than about trying to approach true theories or standpoints that are ac- 
ceptable as such, there is not even a whiff of justificationism in pragma-dialectics. In short, argumentation must be understood from the intended, critical perspective and the argumentative expressions used do not imply any concession to justificationism, other than that expressions such as 'justificatory force' are useful ones. (Garssen and van Laar 2010, pp. 137-9, emphasis in original)

We cite Garssen and van Laar's defense against the charge that P-D theory requires "a whiff of justificationism" at such length because it is particularly clear and helpful in bringing out what is at issue. We think, however, that that defense faces serious problems.

First, even if they are right about what is needed within critical discussions, what they say here does not touch the P-D theorist's need to embrace justificationism insofar as he wishes to defend his theory as superior to other, incompatible, theories (such as, for example, an epistemic one). It is hard to believe that P-D theorists are not embarked on this particular justificatory project. If they are embarked on it, they have no alternative but to appeal to justificationism's notion of positive support. ${ }^{3}$ (See also Section 11 below.)

Setting this aside, are they right that within critical discussions no justificationist notion of positive support is necessary? In the first paragraph cited above, they help themselves to the notion of successful defense. What constitutes success here? If it is that the discussants regard a particular defense as successful, we are back in the land of mere persuasion and consensus: an argument is successful if protagonist and antagonist agree that it is.

That this may be their answer is suggested also by their saying, in the same paragraph, that the 'success' of the argument might well lead to the result "that this person $\mathrm{P}$ will prefer $\mathrm{S}$ as his personal conviction over not-S." Is leading to personal conviction an indicator of an argument's quality? Are there any constraints on what P might adopt 'as his personal conviction'? Can P consider exactly the same information but prefer not-S? The dangers here for P-D theory are manifest.

Garssen and van Laar are at pains to emphasize that the argument's success "does not constitute justification, unless we understand this term in a dialectical fashion." It is for this reason that they insist that there is no "whiff of justificationism" in P-D theory. "Success" here consists in problem validity, conventional validity, and persuasion or personal conviction, in the context of coping

\footnotetext{
${ }^{3}$ They might reply: "But we are not offering a positive defense of P-D theory; we are merely criticizing rival theories." But if those criticisms are meant to constitute positive reasons for rejecting other theories, or for preferring P-D theory to them, they are implicitly appealing to the notion of positive support.
} 
with criticism. If a discussant were persuaded otherwise than he in fact is, given the same conditions and starting points, that would constitute "success" as well.

The denial of a commitment to justificationism comes at the cost of re-conceiving arguments as mere instruments of persuasion or consensus-building and re-defining the normative terms we employ in assessing their quality accordingly. (We discuss Garssen and van Laar's explicit defense of doing just that in Section 10 below). This is the same dilemma showing up in a different form, again, as a choice between accepting an epistemic account and changing the subject.

Garssen and van Laar are clear that P-D theory is, as we will put it, epistemically unambitious: "the pragma-dialectical theory of argumentation remains restricted to the investigation of standpoints in the light of particular sets of starting points. Given that the pragma-dialectical theory is about defending standpoints against an addressee with a particular set of commitments, rather than about trying to approach true theories or standpoints that are acceptable as such, there is not even a whiff of justificationism in pragmadialectics." That is, P-D theory is not interested in evaluating arguments or critical discussions in terms of truth or justificatory force. Of course, it is the P-D theorist's right to be unambitious in this way. But then it is unclear why he should want to retain and utilize the key normative terms of epistemology in his epistemically unambitious theory. Let us grant that it is his right to stipulatively redefine such terms as he wishes. (See Section 10 below.) There are still two questions: (a) Would it not be clearer to use a different terminology? (b) If 'successful defense' is understood in terms of "defending standpoints against an addressee with a particular set of commitments", should not more be involved than that the speech acts made in the discussion obey the P-D rules and honor those commitments? If not, opposing results of identical critical discussions will both count as "successful."

All these comments point in the same direction: our original complaint, that an argument, conclusion, or standpoint can be P-D rational and yet completely irrational from the epistemic point of view, has been conceded.

\section{A misguided criticism of the epistemic approach}

Garssen and van Laar also criticize the epistemic view as follows:

The epistemic alternative is based "on the claim that it is a conceptual truth about arguments that their central (not, of course, only) purpose is to provide a bridge from known truths or justified beliefs to as yet unknown (or at least un- 
recognized) truths or as yet unjustified beliefs" (1992: p. 92).

What is striking about this view is that it seems to imply an unacceptable restriction of the type of issues that can be raised in discussion. Political or legal argumentation that is put forward in defense of practical standpoints seems to be disregarded. For it is only in a stretched use of the term that we can say that it is true that something ought to be done or that the prudence of an action is the object of a belief. What is more, from a dialectical stance, the notions "known truth" and "justified belief" need further clarification. Who is to decide that a certain statement is a "known truth" or a "justified belief," in case the matter is contentious? (Garssen and van Laar 2010, p. 129, emphases in original, note deleted, citing Biro and Siegel 1992.)

The "restriction" Garssen and van Laar here envision is no restriction at all. Nothing in the epistemic view - and certainly not the cited passage concerning the "conceptual truth about arguments"suggests that there cannot be arguments about moral, prudential, political and legal matters. It is often true (in whatever sense of that term your favorite theory of truth favors) that some particular thing ought to be done ("[It is true that] the torturers should stop torturing immediately"); we routinely believe propositions involving the prudence of an action ("You really want to attend that conference, and time is running out, so [I believe that] you had better make your flight reservations quickly"). Moreover, their complaint here conflates what an argument is about with what an argument is. The former makes no difference to the latter. Nor should what an argument is about affect how it is evaluated qua argument (Biro 2009). Our use of 'truth' and 'belief' in the cited passage, then, is not "stretched" at all.

We assume that, "from a dialectical stance", the "further clarification" Garssen and van Laar here call for is easy to provide: from that stance, "known truth" and "justified belief" would both be understood dialectically, in terms of what the participants in the discussion agree about. Our claim is, of course, not made "from a dialectical stance" and it presents no special difficulties for analyzing the concepts involved. If the objection is that we do not give an analysis of them, our reply is that that is not the task of a theory of argumentation. Such a theory is entitled to use concepts whose analysis is the business of the theory of knowledge or the theory of truth. (Compare: an analysis of knowledge as justified true belief is not obligated to give a theory of truth.) Or, perhaps, the complaint is that the concepts we are using - those of truth, knowledge, justified belief-are somehow defective, since there is no adequate 
analysis of them. Then, of course, all we have left is what P-D traffics in: persuasion and agreement - if even that. But while we have not taken on the task of refuting relativism, we cheerfully admit to assuming its falsity here. ${ }^{4}$

\section{The "Handsome/Racist" and "Gambler's Fallacy" Examples}

Garssen and van Laar's discussion of our proposed counterexamples to P-D theory is helpful in further clarifying the dispute. About our example of the handsome but otherwise unqualified candidate, they write:

Biro and Siegel point out that the outcome of the discussion is patently irrational, since the participants' shared belief that handsomeness is an appropriate criterion is itself unjustified. In this case a resolution has been reached in accordance with the pragma-dialectical code of conduct but this result of the discussion is "nevertheless unjustified or irrational" (1992: p. 90). This makes them conclude that pragma-dialectical rationality or reasonableness is not the kind of reasonableness we are after....

We leave it up to the various disciplines to provide methods and criteria that help scholars to assess the acceptability of premises, and we leave it up to individual disputants to create what they conceive of as an appropriate common ground. But we assign argumentation theory the task of examining how to converse reasonably on the basis of whatever is deemed acceptable by parties. (Garssen and van Laar 2010, pp. 126-7, citing Biro and Siegel 1992.)

We are happy to grant that the P-D model of a critical discussion provides a model for understanding how agreements can be reached by critical discussants - that is, how resolutions of disputes can be reached, by means of rules (and moves sanctioned by those rules) that both discussants accept as legitimate or permissible, which utilize agreed-upon material starting points. That is, we have no problem with the P-D notions of problem validity and conventional validity. We reiterate, though, that the normative status of such problem- and conventional-valid resolutions remains up in the air, since, as Garssen and van Laar concede, both the starting points - the "points of departure adopted by the parties" (Garssen and van Laar 2010, p. 128) - and the rules can be epistemically de-

\footnotetext{
${ }^{4}$ One of us has taken on this task elsewhere. See, most recently, Siegel (2010).
} 


\section{Harvey Siegel and John Biro}

fective. The examples of the handsome candidate and the gambler's fallacy illustrate this; nothing Garssen and van Laar say challenges them. Their response is, in effect: The P-D approach is not challenged by these examples or accompanying considerations, because the approach offers a conception of reasonableness according to which the reasonableness or otherwise of argumentative moves depends not on the epistemic status of agreed-upon points of departure or rules of inference or reasoning, but only on whether they achieve agreement and whether the speech acts that make up the discussion, as judged by the P-D rules governing critical discussions, are permissible. Which is, once again, precisely our point: 'PD-reasonableness' does not amount to epistemic rationality or reasonableness. But the latter is what a theory of arguments and argumentation must provide (Biro and Siegel 1992, p. 90-91; Biro and Siegel 2006, p. 7). Garssen and van Laar say nothing here to challenge either the status of the examples as counter-examples, or the conceptual truth about arguments that we emphasize. Again, they concede our basic criticism of the P-D approach.

\section{Pragma-dialectics and the meanings of normative terms}

Garssen and van Laar make it clear that the crucial normative terms at the center of the present disagreement are redefined by P-D theorists:

'[A]rgument', 'pro-argumentation', 'justificatory force', and related expressions, have in pragma-dialectics been provided with a non-justificationist meaning. (Garssen and van Laar 2010, p. 134.)

What are these different meanings? As Garssen and van Laar explain, the differences in meaning flow from the fact that

[a]ccording to the pragma-dialectical theory, argumentation must be examined from the perspective of a critical discussion....

Due to this dialectical setting, the argumentative terminology has been provided with content that is not justificationist in character. First, the protagonist puts forward argumentation in response to challenges by the antagonist. It is the antagonist who, by posing critical questions, objections and requests for clarification, points at the components of the protagonist's position that are considered in need of further support or clarification. In short, argumentation, in the dialectical sense of the term, is not an at- 
tempt to find a more or less firm foundation, but nothing more nor less than coping with criticism.

Second, argumentation is part of a cooperative examination into the issue of whether the standpoint of the protagonist is to be accepted by the antagonist, given the starting points that the parties have agreed upon in the opening stage....[W]e say that all good arguments are "critical" and aimed at testing the critical position of the antagonist. In short, argumentation forms a part of a mutual investigation into the acceptability of a standpoint, and therefore into the tenability of both the position of the protagonist and of the antagonist. Different from what Biro and Siegel seem to suppose (2008), critical rationalistic argumentation theorists do not need to avoid all uses of terms such as 'argument', 'pro-argumentation' and 'justificatory force'

...It is clear that in our understanding, "criticism" aimed at weeding out errors is primary and that argument is better seen as a by-product of the critical process than as the device with which to guarantee a position in a secure enough foundation. (Garssen and van Laar 2010, pp. 1367 , emphasis ours. $)^{5}$

How exactly do 'criticism' and 'critical' work in the assessment of actual disputes, according to Garssen and van Laar? Consider the following schematized critical discussion:

Protagonist: $p, q$, therefore probably $r$. You should accept or believe $r$ on the basis of the reasons offered.

Antagonist: I don't think $p$ and $q$ constitute good reasons for believing $r$, because $s$.

Protagonist: Yes they do, because $t$. Besides, not- $s$, because $u$.

\footnotetext{
${ }^{5}$ Garssen and van Laar in their paper appeal to critical rationalists such as Miller, Bartley, and Popper and others. They do not, however, address the fundamental criticisms of the critical rationalist position that have been standard in the philosophy of science literature for decades, ones that we rehearse in our 2008. We will not dwell on those difficulties here, but simply point out that citing these authors, whose arguments for critical rationalism and against the possibility of positive support have, we think, been thoroughly discredited, does not advance the dialectic. (For a more recent discussion, see Irzik 2008.)
} 
Protagonist asserts and offers reasons for a particular standpoint $r$, Antagonist raises an objection to that standpoint, and Protagonist defends the original standpoint and offers a consideration meant to cast doubt on Antagonist's criticism. Let us assume that none of the speech acts that make up the critical discussion contravene either the rules or the starting points that the parties have agreed upon. Assume further a definitive filling out of the discussion. Our question: has either participant coped with the criticisms offered? Should Protagonist continue to assert that $r$, in the face of the criticism advanced by Antagonist? Should Antagonist give up her criticism of $r$, in the light of Protagonist's defense of $r$ and criticism of $s ?$

We do not think that any of the responses Garssen and van Laar can make here can succeed in upending our fundamental criticism. Here are the options:

i. The discussion is problem valid and conventionally valid. That is enough to say that both parties have coped with the criticisms offered. This answer shows the emptiness of "coping with criticism": if such coping requires merely that problem- and conventional validity be preserved and maintained, the discussion does not even have to resolve the dispute. So, both parties can be said to have coped with the criticisms offered, even though neither changes her view.

ii. The discussion is problem valid and conventionally valid, and the difference of opinion has been resolved (in either direction). Therefore we should say that both parties have coped with the criticisms offered. This answer has it that "coping with criticism" amounts to one party rejecting the criticism offered by her opponent, and the other accepting her opponent's criticisms as telling or persuasive. That is, coping is a matter of one discussant standing pat, and the other capitulating to her opponent's point of view. It has nothing to do with whether either one ought to stand pat or capitulate. It is just a matter of persuasion.

iii. The discussion is problem valid and conventional valid, and the difference of opinion has been resolved in one direction or the other on the basis of the superior epistemic merit of one of the criticisms. Only then should we say that both parties have coped with the criticisms offered: both have recognized the "validity" or justificatory force of one of the criticisms 
offered and that criticism provides good reason for giving up the standpoint or criticism successfully criticized. This makes coping a matter of epistemic evaluation.

None of these options challenges our basic criticism. The fundamental problem is this: if "coping with criticism" is understood in either of the first two ways, then it is independent of the quality of the criticism in question. If it is understood in the third way, the epistemic account has been vindicated.

Consider the matter from the perspective of a participant in a critical discussion: "My opponent has criticized my standpoint (or my criticism of her standpoint). Should I reject the criticism and continue to hold my original view, or accept it and give up that view?" We see nothing in Garssen and van Laar's discussion that answers the question in a theoretically helpful or satisfying way. In particular, if the participant decides to do one or the other, does that decision need, on their account, to be based on good reasons? If Garssen and van Laar answer in the negative, then "coping" is empty; any decision is as "good" as any other. If they answer affirmatively, then positive support has found its way back into their account. Without specifying criteria of appropriate coping, anything can count as "coping with criticism." (Popper is famously said to have coped with criticism by turning off his hearing aid.) To make the notion relevant to the evaluation of arguments, coping must be understood as responding in a way that is sensitive to the content of the criticism.

Finally, if all the key terms, including 'argument' itself, are redefined in P-D terms, can the P-D theory be rightly regarded as a theory of argument (in the ordinary sense) at all?

\section{A Self-Reflexive Difficulty}

It is worth asking: how does the P-D approach apply to an argumentative exchange of the sort in which Garssen and van Laar and we are now engaged? We take it as obvious that we are arguing with Garssen and van Laar about the adequacy of the P-D conception of reasonableness: they think it is adequate, we do not. The four of us have not sat down and agreed upon either material starting points or permissible rules of reasoning and inference. That is, we have not agreed upon "points of departure." Does this mean that ours is not a critical discussion? If so, the P-D model is inapplicable to many 'real world' (political, economic, religious, etc.) disputes, and to virtually all substantive scholarly disputes. If notthat is, if our discussion with Garssen and van Laar (and van Eemeren and Grootendorst) counts as a critical discussion to which 
the P-D theory is applicable despite its failing to satisfy the model's limitation to disputes in which agreement on material starting points and rules of reasoning and inference is established in the opening stage - then that theory is problematic, since many, perhaps most, disputes of interest (including the present one) do not satisfy the theory's constraints and yet are the sort of dispute to which the theory is intended to apply.

A further, related difficulty, stemming from Garssen and van Laar's redefinition of the key terms of interest to argumentation theory, is that, so understood, the P-D theory seems to undercut its ability to criticize rival theories. Consider: are Garssen and van Laar's criticisms of our epistemic theory offered as epistemically forceful criticisms, or only as PD-criticisms? If the former, are the key terms not fully redefined after all? If the latter, why should anyone who does not embrace their redefinitions care about them?

\section{Conclusion}

Garssen and van Laar's discussion helps to clarify the relative merits of the P-D theory and of our criticisms of it. We are now in a position to see clearly that Garssen and van Laar have conceded our main criticism of the P-D theory; that that theory does not conform to the conceptual truth concerning arguments that rightly constrains theories of argument; and that in failing to so conform, it is far more limited in theoretical interest than is often claimed. While the pragma-dialectical theory may indeed provide the tools needed to enable us to make some normative evaluations of arguments, and indeed provides the most sophisticated and rightly esteemed account of critical discussions extant, the limitation of its normative evaluations to 'evaluations in the pragma-dialectical sense' makes it unable to provide an adequate account of how arguments should be (and are) evaluated. ${ }^{6}$

\section{References}

Biro, J. (2009). An argument is an argument is an argument.... Paper presented at International Symposium "Argumentation and Philosophy: Different Issues or Productive Tensions?" Instituto de Investigaciones Filosóficas, Universidad Autónoma de México, September 2009.

\footnotetext{
${ }^{6}$ Thanks to Christoph Lumer for helpful discussion of an earlier draft.
} 
Biro, J. \& H. Siegel. (1992). Normativity, argumentation and an epistemic theory of fallacies. In F.H. van Eemeren, R. Grootendorst, J.A. Blair and C.A. Willard (Eds.), Argumentation Illuminated (pp. 85-103, Ch. 7). Amsterdam: SicSat.

Biro, J. \& H. Siegel. (2006). Pragma-dialectic versus epistemic theories of arguing and arguments: Rivals or partners? In P. Houtlosser \& A. van Rees (Eds.), Considering pragmadialectics: A festschrift for Frans $H$. van Eemeren on the occasion of his $60^{\text {th }}$ birthday (pp. 1-10, Ch. 1). Mahwah, NJ: Erlbaum.

Biro, J. \& H. Siegel. (2006a). In defense of the objective epistemic approach to argumentation. Informal Logic 26 (1), 91-101.

Eemeren, F.H. van \& R. Grootendorst. (1984). Speech acts in argumentative discussions. Dordrecht: Foris.

Eemeren, F.H. van \& R. Grootendorst. (1992). Argumentation, communication, and fallacies: A pragma-dialectical perspective. Hillsdale, NJ: Erlbaum.

Eemeren, F.H. van \& R. Grootendorst. (2004). A systematic theory of argumentation: The pragma-dialectical approach. Cambridge: Cambridge University Press.

Garssen, B. \& J.A. van Laar. (2010). A pragma-dialectical response to objectivist epistemic challenges. Informal Logic 30 (2), 122141.

Goodman, N. (1983). Fact, Fiction and Forecast (fourth edition). Cambridge: Harvard University Press.

Irzik, G. (2008). Critical rationalism. In S. Psillos \& M. Curd (Eds.), Routledge Companion to the Philosophy of Science (pp. 58-66, Ch. 6). Abingdon and New York: Routledge.

Klein, P. (1999). Human knowledge and the infinite regress of reasons. In J. Tomberlin (Ed.), Philosophical Perspectives, vol. 13, pp. 297-325.

Klein, P. (2000). Why not infinitism? In R. Cobb-Stevens (Ed.), Epistemology: Proceedings of the Twentieth World Congress in Philosophy, vol. 5, pp. 199-208.

Lehrer, K. (2000). Theory of Knowledge (second edition). Boulder: Westview Press.

Lehrer, K. (2003). Coherence, circularity and consistency: Lehrer replies. In E. J. Olsson (Ed.), The Epistemology of Keith Lehrer. Dordrecht: Kluwer, pp. 309-356.

Lumer, C. (2010). Pragma-dialectics and the function of argumentation. Argumentation 24(1), 41-69.

Siegel, H. (2010). Epistemological Relativism: Arguments pro and con. In S. D. Hales (Ed.), Blackwell Companion to Relativism (in press).

Siegel, H. \& J. Biro (1997). Epistemic normativity, argumentation, and fallacies. Argumentation 11 (3), 277-292. 
480 Harvey Siegel and John Biro

Siegel, H. \& J. Biro (2008). Rationality, reasonableness, and critical rationalism: Problems with the pragma-dialectical view. Argumentation 22 (3), 191-203. 